\title{
The characteristics of a high-power diode laser fired enamel coating on a carbon steel
}

\section{J Lawrence* and L Li}

Laser Processing Research Centre, Department of Mechanical Engineering, University of Manchester Institute of Science and Technology, UK

\begin{abstract}
Significant changes to the wettability characteristics of a common engineering carbon steel (EN8) were effected after high power diode laser (HPDL) surface treatment. These modifications have been investigated in terms of the changes in the surface roughness of the steel, the presence of any surface melting, the polar component of the steel surface energy and the relative surface $\mathrm{O}_{2}$ content of the steel. The morphological and wetting characteristics of the mild steel and the enamel were determined using optical microscopy, scanning electron microscopy, X-ray photoemission spectroscopy, energy-dispersive X-ray analysis and wetting experiments by the sessile drop technique. This work has shown that HPDL radiation can be used to alter the wetting characteristics of carbon steel so as to facilitate improved enamelling. Furthermore, standard mechanical, physical and chemical testing of the HPDL-fired enamel glaze revealed the glaze to possess similar properties to those of a conventionally fired enamel glaze in terms of bond strength, rupture/impact strength, wear and corrosion resistance. Such similar performance can be attributed to the two glazes possessing the same mechanical properties and similar amorphous structure, despite their very different firing techniques.
\end{abstract}

Keywords: laser, steel, enamel, wettability, surface modification, mechanical, physical, chemical, testing

\section{NOTATION}

a constant

$b \quad$ constant

$D_{\mathrm{R}} \quad$ Wenzel type of surface roughness

$F_{\mathrm{R}} \quad$ Cassie-Baxter type of surface roughness

$r$ roughness factor

$W_{\text {ad }} \quad$ work of adhesion

$W_{\text {ad }}^{\mathrm{d}}$ dispersive component of the work of adhesion

$W_{\text {ad }}^{\mathrm{p}}$ polar component of the work of adhesion

$\gamma \quad$ total surface energy

$\gamma^{\mathrm{d}} \quad$ dispersive component of surface energy

$\gamma^{\mathrm{p}} \quad$ polar component of surface energy

$\gamma_{\text {lv }} \quad$ liquid surface energy

$\gamma_{\mathrm{sv}}^{\mathrm{d}} \quad$ dispersive component of solid substrate surface energy

$\gamma_{\mathrm{sv}}^{\mathrm{p}} \quad$ polar component of solid substrate surface energy

$\theta \quad$ contact angle

$\theta_{\text {rad }}$ radial contact angle

The MS was received on 14 February 2000 and was accepted after revision for publication on 28 July 2000.

* Corresponding author: Laser Processing Research Centre, Department of Mechanical Engineering, University of Manchester Institute of Science and Technology (UMIST), PO Box 88, Manchester M60 1QD, UK. $\theta_{\text {th }} \quad$ theoretical contact angle

$\theta_{\mathrm{w}}$ contact angle for the wetting of a rough surface

\section{INTRODUCTION}

The interfacial phenomena between vitreous enamels and carbon steels are of great interest to scientists and engineers alike. This is due primarily to the fact that, in many practical applications where vitreous enamels are fired onto carbon steels, the performance of the article is directly linked to the nature of the enamel-steel interface. Many studies to investigate these phenomena have been carried out; however, they have been principally concerned with the wettability of zirconia and other oxide ceramics on metals $[\mathbf{1}-\mathbf{5}]$ as well as the adhesion of silicone sealants to aluminium [6] and the coating of aluminium alloys with ceramic materials $[7,8]$. The interfacial mechanisms investigated have centred principally around the thermodynamic criterion $[\mathbf{2}, \mathbf{3}, \mathbf{5}]$, the electronic theory [4] and the occurrence of oxidation [1, 9].

To date, very little published work exists pertaining to the use of lasers for altering the surface properties of materials in order to improve their wettability characteristics. Notwithstanding this, it is recognized within the 
currently published work that laser irradiation of a metal surface can bring about changes in the metal's wettability characteristics. Previously Zhou and de Hosson $[7,8]$ carried out work on the laser coating of aluminium alloys with ceramic materials $\left(\mathrm{SiO}_{2}, \mathrm{Al}_{2} \mathrm{O}_{3}\right.$, etc.), reporting on the well-documented fact that generated oxide layers often promote metal-oxide wetting. Further, Heitz et al. [10], Henari and Blau [11] and Olfert et al. [12] have found that excimer laser treatment of metals results in improved coating adhesion. The improvements in adhesion were attributed to the fact that the excimer laser treatment resulted in a smoother surface and as such enhanced the action of wetting. However, the reasons for these changes with regard to changes in the material's surface morphology, surface composition and surface energy are not reported. In contrast, in a more comprehensive study by Lawrence and Li [13], which compared the effects of $\mathrm{CO}_{2}, \mathrm{Nd}: \mathrm{YAG}$, excimer and high power diode laser (HPDL) radiation on the wettability characteristics of a mild steel, it was found that changes in the wettability characteristics of the steel varied depending on the laser type.

The present work details the use of a novel $1.2 \mathrm{~kW}$ HPDL to alter the wettability characteristics of a common engineering carbon steel (EN8) and the effects thereof on the adhesion and bonding characteristics with a vitreous enamel. The intention is to facilitate the hitherto impossible task of enamelling carbon steel in normal atmospheric conditions without pre-treatment chemical cleaning of the steel. Indeed, such a process has been employed by the present authors to facilitate the sealing, by means of laser enamelling, of ceramic tile grouts [14-17].

\section{EXPERIMENTAL PROCEDURES}

The laser used in the study was a $1.2 \mathrm{~kW}$ HPDL (RofinSinar, DL-012), emitting at $940 \mathrm{~nm}$ wavelength. The laser beam was focused directly onto the samples with a $6 \times 20 \mathrm{~mm}^{2}$ rectangular beam at a fixed power of $500 \mathrm{~W}$. The laser was operated in the continuous wave mode. The beam was traversed across the samples by mounting the assembly head onto the $z$ axis of a threeaxis CNC table. The focused laser beam was thus fired across the surface of the mild steel, and then subsequently the enamel frit, by traversing the samples beneath the laser beam using the $x$ and $y$ axes of the CNC table at speeds of $250-2000 \mathrm{~mm} / \mathrm{min}$, while $\mathrm{O}_{2}$ gas was pumped into a gas box in order to assist the surface treatment process.

The liquids used for the wetting experiments were human blood, human blood plasma, glycerol and 4octanol. The test liquids, along with their total surface energy $\left(\gamma_{2}\right)$ as well as the dispersive $\left(\gamma^{\mathrm{d}}\right)$ and polar $\left(\gamma^{\mathrm{p}}\right)$ components, are detailed in Table 1 . An additional set of wetting experiments was conducted simply to
Table 1 Total surface energy $\left(\gamma_{\mathrm{lv}}\right)$ and the dispersive $\left(\gamma_{\mathrm{lv}}^{\mathrm{d}}\right)$ and polar $\left(\gamma_{\mathrm{lv}}^{\mathrm{p}}\right)$ components for the selected test liquids [15]

\begin{tabular}{llll}
\hline Liquid & $\begin{array}{l}\gamma \\
\left(\mathrm{mJ} / \mathrm{m}^{2}\right)\end{array}$ & $\begin{array}{l}\gamma_{\mathrm{lv}}^{\mathrm{d}} \\
\left(\mathrm{mJ} / \mathrm{m}^{2}\right)\end{array}$ & $\begin{array}{l}\gamma_{\mathrm{lv}}^{\mathrm{p}} \\
\left(\mathrm{mJ} / \mathrm{m}^{2}\right)\end{array}$ \\
\hline Human blood & 47.5 & 11.2 & 36.3 \\
Human blood plasma & 50.5 & 11.0 & 39.5 \\
Glycerol & 63.4 & 37.0 & 26.4 \\
4-Octanol & 27.5 & 7.4 & 20.1 \\
\hline
\end{tabular}

determine the contact angle between the enamel and the mild steel before and after laser treatment.

The solid materials used as substrates in the wetting experiments were rectangular billets $\left(50 \times 100 \mathrm{~mm}^{2}\right.$ with a thickness of $3 \mathrm{~mm}$ ) of common engineering low carbon mild steel (EN8). The contact surfaces of the materials were used as received in the experiments. The enamel used was commercially available enamel frit (Ferro) which, in order to form a manageable paste, was mixed with $20 \mathrm{wt} \%$ white spirit. The composition of the enamel consisted mainly of the following: $\mathrm{SiO}_{2}$, $\mathrm{B}_{2} \mathrm{O}_{3}, \mathrm{Na}_{2} \mathrm{O}, \mathrm{Mn}$ and small quantities of $\mathrm{Pb}, \mathrm{Ba}, \mathrm{MgO}$, $\mathrm{Al}_{2} \mathrm{O}_{3}$ and $\mathrm{Ni}$; the powder size was less than $25 \mu \mathrm{m}$ medium size. The morphological and physical characteristics of the mild steel and the enamel were determined using optical microscopy, scanning electron microscopy (SEM), X-ray photoemission spectroscopy (XPS) and energy-dispersive X-ray (EDX) analysis.

The wetting experiments were carried out in atmospheric conditions at a temperature of $20^{\circ} \mathrm{C}$. The droplets were released in a controlled manner onto the surface of the mild steel substrate (treated and untreated) from the tip of a micropipette, with the resultant volume of the drops being approximately $6 \times 10^{-3} \mathrm{~cm}^{3}$. Each experiment lasted for $3 \mathrm{~min}$ with profile photographs of the sessile drops being obtained every minute, with the contact angle subsequently being measured. The experimental results showed that throughout the period of the tests no discernible change in the magnitude of the contact angle occurred.

\section{GLAZE GENERATION CHARACTERISTICS}

\subsection{Enamel glaze characteristics}

It was observed that, prior to laser irradiation, it was not possible to fire the enamel onto the as-received surface of the mild steel. Indeed, laser interaction with the enamel when it was placed on the untreated mild steel surface simply resulted in the 'balling' of the enamel (the formation of small spheres approximately the diameter of the laser beam itself). Such observations are in accord with those of Bourell et al. [18] and Agarwala et al. [19], who noted the balling phenomenon during laser sintering work of silica-based materials. After HPDL surface 


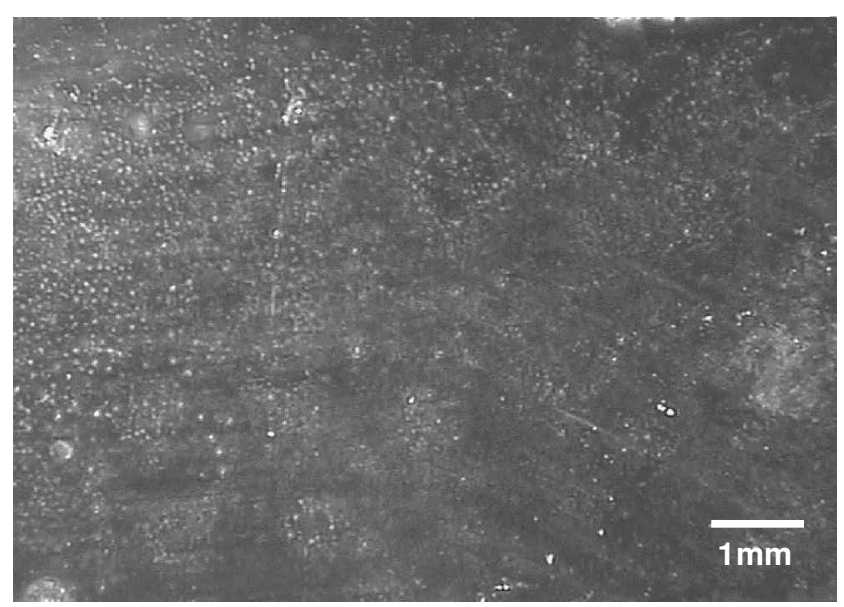

Fig. 1 Typical surface morphology of the HPDL-fired enamel glaze on the mild steel $\left(2 \mathrm{~kW} / \mathrm{cm}^{2}\right.$ power density, $480 \mathrm{~mm} / \mathrm{min}$ traverse speed)

treatment of the mild steel, however, it was possible to fire the enamel directly onto the mild steel. The mechanism of this phenomenon is based entirely on the wettability characteristics of the mild steel.

Figure 1 shows the typical surface morphology of the HPDL-fired enamel glaze on the mild steel. The glaze was typically slightly undulating, with the undulations being regular in both periodicity and intensity. The thickness of the glaze was regular across the surface, being typically around $450 \mu \mathrm{m}$. Moreover, the glaze displayed no cracks or porosities. Such glazes could be generated within a small laser parameter operating window of $1.75-2.5 \mathrm{~kW} / \mathrm{cm}^{2}$ power density and $480-$ $600 \mathrm{~mm} / \mathrm{min}$ traverse speed.

\subsection{Contact angle and wettability characteristics}

When a drop of liquid is in contact with a solid surface, the final shape taken by the drop, and thus whether it will wet the surface or not, depends on the relative magnitudes of the molecular forces that exist within the liquid (cohesive) and between the liquid and the solid (adhesive) [20]. The index of this effect for an ideal surface is the contact angle, $\theta$, which the liquid subtends with the solid. The adhesion intensity of a liquid to a solid surface is known as the work of adhesion, $W_{\mathrm{ad}}$, and is related to the liquid surface energy, $\gamma_{\mathrm{lv}}$, by the Young-Dupre equation:

$$
W_{\mathrm{ad}}=\gamma_{\mathrm{lv}}(1+\cos \theta)
$$

It is important to consider also the influence of the substrate surface roughness on the wetting contact angle. Rough grooves on a surface, which may contribute to the influence of contact angles, can be categorized as either radial or circular grooves. Any practical rough surface can be represented by a combination of these two cases [21]. In fact two roughness parameters can be defined: the Wenzel type, $D_{\mathrm{R}}$ [22], and the CassieBaxter type, $F_{\mathrm{R}}$ [23]. In the case that wetting spreads radially, as is the likely case with the mild steel, then the resulting radial contact angle, $\theta_{\text {rad }}$, is related to the theoretical contact angle, $\theta_{\text {th }}$, by

$$
\cos \theta_{\mathrm{rad}}=D_{\mathrm{R}}\left(1-F_{\mathrm{R}}\right) \cos \theta_{\mathrm{th}}-F_{\mathrm{R}}
$$

According to Neumann and Good [24], only if $F_{\mathrm{R}}$ is equal to zero can a model similar to that for heterogeneous solid surfaces be developed in order to account for surface irregularities, being given by Wenzel's equation:

$$
r\left(\gamma_{\mathrm{sv}}-\gamma_{\mathrm{sl}}\right)=\gamma_{\mathrm{lv}} \cos \theta_{\mathrm{w}}
$$

where $r$ is the roughness factor defined as the ratio of the real and apparent surface areas and $\theta_{\mathrm{w}}$ is the contact angle for the wetting of a rough surface. It is important to note that Wenzel's treatment is only effective at the position of the wetting triple line [21]. Nevertheless, equation (3) shows clearly that the influence of surface roughness on the contact angle is to cause an increase in the contact angle. Thus, the smoother the contact surface is, then the smaller the contact angle will be.

Optical micrographs of a sessile drop of enamel $\left(20^{\circ} \mathrm{C}\right)$ placed on the surface of the mild steel before and after HPDL irradiation with the contact angle superimposed are shown in Figs $2 \mathrm{a}$ and $2 \mathrm{~b}$ respectively. As one can see from Fig. 2, HPDL irradiation of the mild steel surface effected a considerable reduction in the enamel contact angle.

One explanation for this observed reduction in the enamel contact angle is that the surface obtained after laser treatment was somewhat smoother than the original untreated surface. The mean surface roughness $\left(R_{\mathrm{a}}\right)$ value of the surface of the as-received mild steel was $1.46 \mu \mathrm{m}$, while for the HPDL-treated mild steel surface the mean $R_{\mathrm{a}}$ value was $1.12 \mu \mathrm{m}$. Similar laser-induced surface smoothing effects were obtained by Nicolas et al. [25] and Henari and Blau [11], who observed that excimer laser treatment of ceramics and metals could result in the generation of a smoother surface. Thus, according to equation (2), the smoother surface will inherently result in a reduction in the contact angle. Indeed, this fact is borne out somewhat by Fig. 3, which shows that the surface condition of the mild steel resulting from HPDL modification (with a number of different traverse speeds) greatly affected the measured contact angle.

As can be seen from Fig. 3, at relatively low traverse speeds excess energy is deposited on the surface of the mild steel resulting in a high level of surface melting. This in turn causes porosities and a generally rough surface profile. As the traverse speed increases, however, the energy deposited on the surface of the mild steel decreases. Accordingly the degree of surface melting decreases ultimately to the optimum degree, resulting 


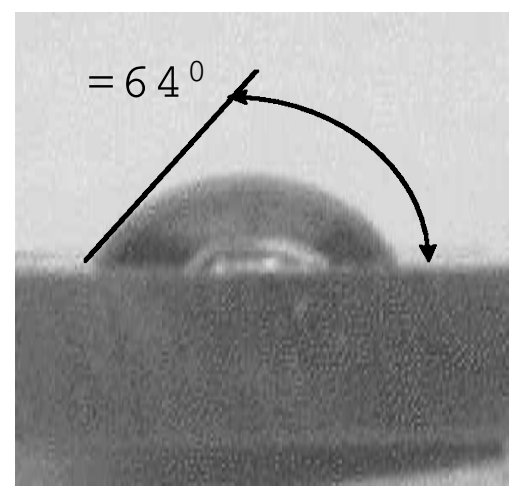

(a)

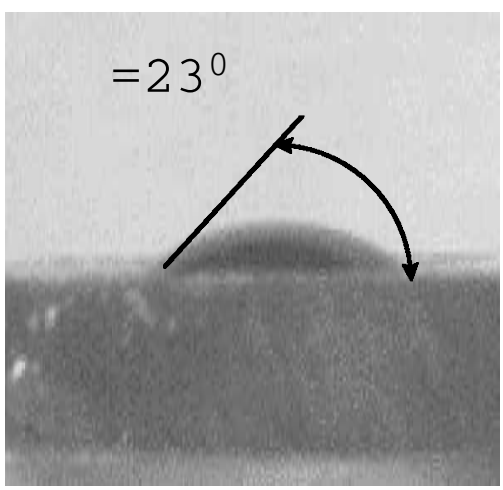

(b)

Fig. 2 Contact angles for the enamel on (a) the as-received mild steel surface and (b) the HPDL-treated mild steel surface $(1500 \mathrm{~mm} / \mathrm{min}$ traverse speed)

in the minimum surface roughness, and contact angle, at around $1500 \mathrm{~mm} / \mathrm{min}$. Beyond this point the surface roughness, and contact angle, can be seen to increase, indicating that insufficient melting, and consequently smoothing, was achieved.

Such results are in accord with those obtained by Feng et al. [26], who noted that, under certain surface conditions, contact angle reduction was inversely proportional to surface roughness. Moreover, Olfert et al. [12] found that excimer laser treatment of steel surfaces greatly improved the adhesion of a zinc coating. They asserted that laser treatment occasioned the smoothing of many of the high frequency surface features, resulting in more complete wetting by the zinc.

In addition, the improvement in the wetting action experienced by the mild steel can be ascribed in some part to the increase in the surface $\mathrm{O}_{2}$ content of the mild steel following HPDL treatment, since this is known to increase the likelihood of wetting $[\mathbf{1}, \mathbf{9}]$. Indeed, since wetting is governed by the first atomic layers of the surface of a material, the $\mathrm{O}_{2}$ content at the surface of the mild steel before and after HPDL treatment was determined using XPS. The surface $\mathrm{O}_{2}$ content was found to have increased after HPDL treatment from 34 to 40 at $\%$. Clearly, oxidization of the HPDL-treated surface of the mild steel has occurred, thus indicating that $\mathrm{O}_{2}$ enrichment of the laser-treated mild steel surface was active in promoting wetting and adhesion $[\mathbf{1}, \mathbf{9}]$.

\subsection{Mild steel surface energy and its dispersive-polar characteristics}

The intermolecular attraction which is responsible for surface energy, $\gamma$, results from a variety of intermolecular forces whose contribution to the total surface energy is

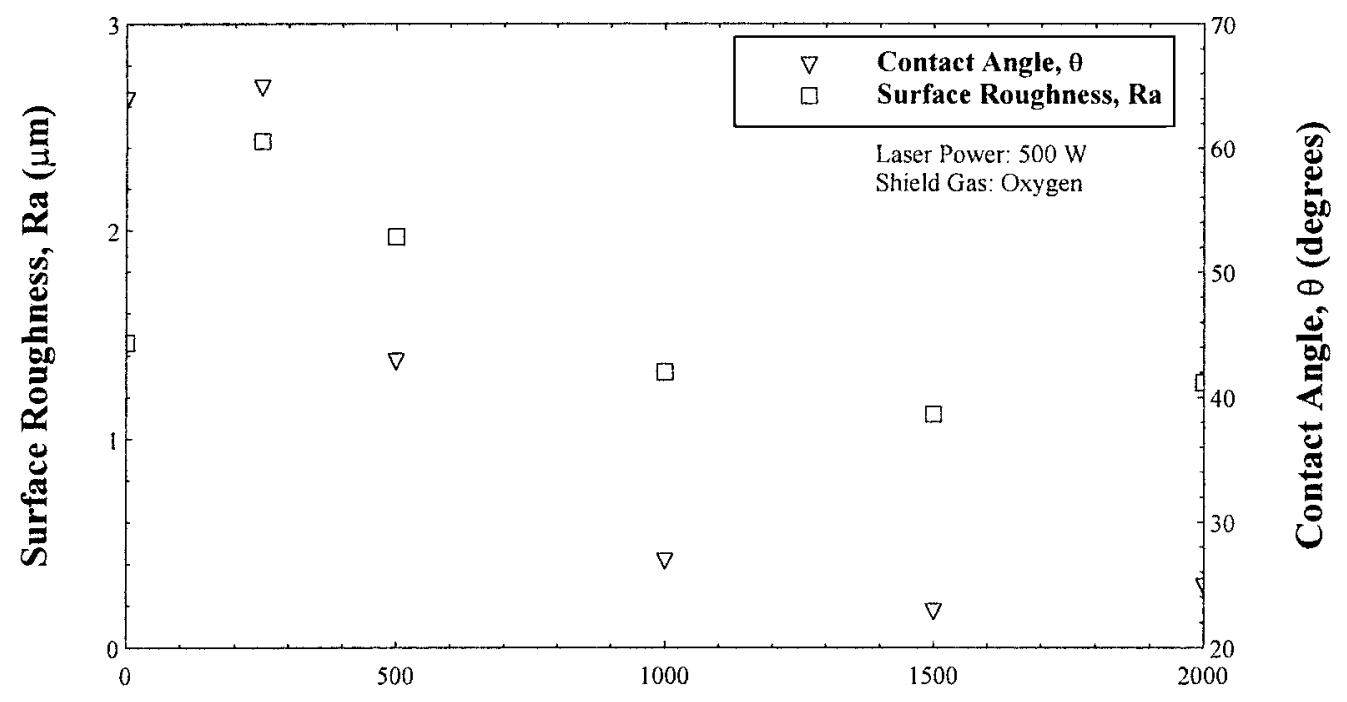

\section{Traverse Speed $(\mathrm{mm} / \mathrm{min})$}

Fig. 3 Relationship between surface roughness, contact angle and traverse speed for the mild steel 


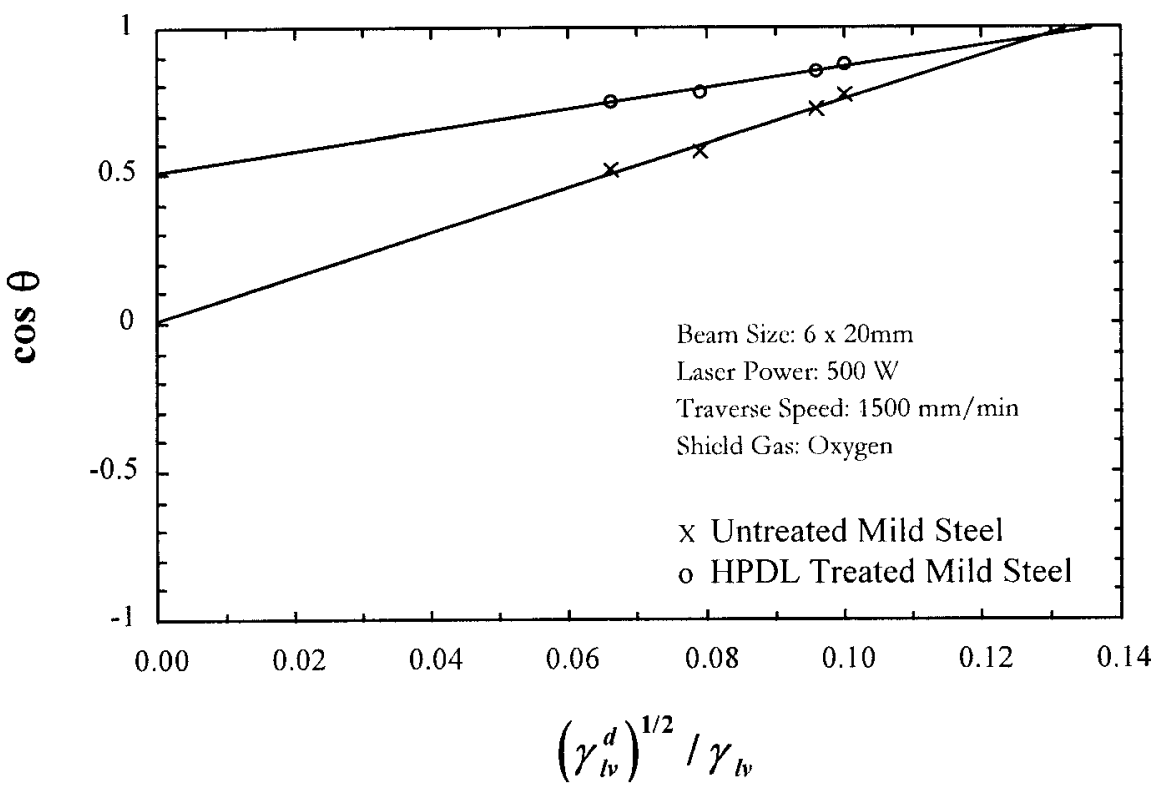

Fig. 4 Plot of $\cos \theta$ against $\left(\gamma_{\mathrm{lv}}^{\mathrm{d}}\right)^{1 / 2} / \gamma_{\mathrm{lv}}$ for the untreated and HPDL-treated mild steel in contact with the wetting test control liquids

additive [27]. The majority of these forces are functions of the particular chemical nature of a certain material, and as such the total surface energy $(\gamma)$ comprises $\gamma^{\mathrm{p}}$ (polar or non-dispersive interaction) and $\gamma^{\mathrm{d}}$ (dispersive component). Therefore, the surface energy of any system may be described by [15]

$$
\gamma=\gamma^{\mathrm{d}}+\gamma^{\mathrm{p}}
$$

As such, $W_{\text {ad }}$ can be expressed as the sum of the different intermolecular forces that act at the interface [27]:

$$
W_{\mathrm{ad}}=W_{\mathrm{ad}}^{\mathrm{d}}+W_{\mathrm{ad}}^{\mathrm{p}}=2\left(\gamma_{\mathrm{sv}}^{\mathrm{d}} \gamma_{\mathrm{lv}}^{\mathrm{d}}\right)^{1 / 2}+2\left(\gamma_{\mathrm{sv}}^{\mathrm{p}} \gamma_{\mathrm{lv}}^{\mathrm{p}}\right)^{1 / 2}
$$

By equating equation (5) with equation (1), the contact angle for solid-liquid systems can be related to the surface energies of the corresponding liquid and solid by

$$
\cos \theta=\frac{2\left(\gamma_{\mathrm{sv}}^{\mathrm{d}} \gamma_{\mathrm{lv}}^{\mathrm{d}}\right)^{1 / 2}+2\left(\gamma_{\mathrm{sv}}^{\mathrm{p}} \gamma_{\mathrm{lv}}^{\mathrm{p}}\right)^{1 / 2}}{\gamma_{\mathrm{lv}}}-1
$$

It is possible to estimate the dispersive component of the mild steel's surface energy, $\gamma_{\mathrm{sv}}^{\mathrm{d}}$, by using equation (6) and plotting the graph of $\cos \theta$ against $\left(\gamma_{\text {lv }}^{\mathrm{d}}\right)^{1 / 2} / \gamma_{\text {lv }}$ (Fig. 4). Thus the value of $\gamma_{\mathrm{sv}}^{\mathrm{d}}$ is estimated by the gradient $\left[=2\left(\gamma_{\mathrm{sv}}^{\mathrm{d}}\right)^{1 / 2}\right]$ of the line which connects the origin $(\cos \theta=-1)$ to the intercept point of the straight line [ $\cos \theta$ against $\left.\left(\gamma_{\mathrm{lv}}^{\mathrm{d}}\right)^{1 / 2} / \gamma_{\mathrm{lv}}\right]$ correlating the data point with the abscissa at $\cos \theta=1$ [28]. The value of $\gamma_{\mathrm{sv}}^{\mathrm{d}}$ for the untreated and HPDL-treated $(1500 \mathrm{~mm} / \mathrm{min}$ traverse speed) mild steel is shown in Table 2 . From the best-fit plots of $\cos \theta$ against $\left(\gamma_{\mathrm{lv}}^{\mathrm{d}}\right)^{1 / 2} / \gamma_{\mathrm{lv}}$, it was found that the ordinate intercept point of the untreated mild steelliquid system was closer to $\cos \theta=-1$ than that of the HPDL-treated mild steel-liquid system. This indicates that, in principle, dispersion forces are acting mainly at the mild steel-liquid interface, resulting in poor adhesion $[28,29]$. In contrast, the best-fit straight line for the HPDL-treated mild steel-liquid system intercepted the ordinate considerably higher above the origin. This is indicative of the action of polar forces across the interface, in addition to dispersive forces, and hence improved wettability and adhesion is promoted [28, 29].

It is not possible to determine the value of the polar component of the mild steel's surface energy, $\gamma_{\mathrm{sv}}^{\mathrm{p}}$, directly from plots of $\cos \theta$ against $\left(\gamma_{\mathrm{lv}}^{\mathrm{d}}\right)^{1 / 2} / \gamma_{\mathrm{lv}}$. This is because the intercept of the straight line [ $\cos \theta$ against $\left.\left(\gamma_{\mathrm{lv}}^{\mathrm{d}}\right)^{1 / 2} / \gamma_{\mathrm{lv}}\right]$ is at $2\left(\gamma_{\mathrm{sv}}^{\mathrm{p}} \gamma_{\mathrm{lv}}^{\mathrm{p}}\right)^{1 / 2} / \gamma_{\mathrm{lv}}$, and thus refers only to individual control liquids and not to the control liquid system. However, it has been established that the entire amount of the surface energies due to dispersion forces either of the solids or the liquids is active in the wettability performance $[28,30]$. It is therefore possible to calculate the dispersive component of the work of adhesion, $W_{\mathrm{ad}}^{\mathrm{d}}$, using only the relevant part of equation (5) thus:

$$
W_{\mathrm{ad}}^{\mathrm{d}}=2\left(\gamma_{\mathrm{sv}}^{\mathrm{d}} \gamma_{\mathrm{lv}}^{\mathrm{d}}\right)^{1 / 2}
$$

The results revealed that, for each particular control liquid in contact with both the untreated and laser

Table 2 Determined surface energy values for the mild steel before and after laser irradiation

\begin{tabular}{lll}
\hline $\begin{array}{l}\text { Surface energy } \\
\text { characteristic }\end{array}$ & $\begin{array}{l}\text { Untreated mild } \\
\text { steel }\left(\mathrm{mJ} / \mathrm{m}^{2}\right)\end{array}$ & $\begin{array}{l}\text { HPDL-treated mild } \\
\text { steel }\left(\mathrm{mJ} / \mathrm{m}^{2}\right)\end{array}$ \\
\hline $\begin{array}{l}\text { Dispersive component, } \gamma_{\mathrm{sv}}^{\mathrm{d}} \\
\text { Polar component, } \gamma_{\mathrm{sv}}^{\mathrm{p}}\end{array}$ & 64.6 & 66.2 \\
\hline
\end{tabular}


treated mild steel surfaces, $W_{\text {ad }}$ could be correlated with $W_{\text {ad }}^{\text {d }}$ by the straight line relationship

$$
W_{\mathrm{ad}}=a W_{\mathrm{ad}}^{\mathrm{d}}+b
$$

where $a$ and $b$ are constants unique to each control liquid system. Also, for the control test liquids used, a linear relationship between the dispersive and polar components of the control test liquids surface energies has been deduced which satisfies the equation

$$
\left(\gamma_{\mathrm{lv}}^{\mathrm{p}}\right)^{1 / 2}=1.3\left(\gamma_{\mathrm{lv}}^{\mathrm{d}}\right)^{1 / 2}+1.15
$$

By introducing equation (8) into equation (5) and rearranging,

$$
W_{\mathrm{ad}}^{\mathrm{p}}=(a-1) W_{\mathrm{ad}}^{\mathrm{d}}+b
$$

By combining equation (10) with equation (5) and differentiating with respect to $\left(\gamma_{\mathrm{lv}}^{\mathrm{d}}\right)^{1 / 2}$, the following can be derived:

$$
\left(\gamma_{\mathrm{sv}}^{\mathrm{p}}\right)^{1 / 2}=\frac{\left(\gamma_{\mathrm{sv}}^{\mathrm{d}}\right)^{1 / 2}(a-1)}{1.3}
$$

From a plot of the linear relationship between $W_{\text {ad }}$ and $W_{\mathrm{ad}}^{\mathrm{d}}, a$ (the gradient of the relationship between $W_{\mathrm{ad}}$ and $W_{\text {ad }}^{\mathrm{d}}$ ) was determined for the untreated and lasertreated mild steel. Since $\gamma_{\mathrm{sv}}^{\mathrm{d}}$ has already been determined for the untreated and laser-treated mild steel from the plots of equation (6), it is possible to calculate $\gamma_{\mathrm{sv}}^{\mathrm{p}}$ for untreated and laser-treated mild steel using equation (11) (see Table 2).

As Table 3 shows clearly, HPDL treatment of the surface of the mild steel has led to a small increase in the polar component of the surface energy, $\gamma_{\mathrm{sv}}^{\mathrm{p}}$, thus improving the action of wetting and adhesion. It is surmised that this increase may be due to HPDL-induced changes in the surface microstructure of the mild steel.

It is important to note that, because of the long-range ionic interactions in the mild steel and the nature of the interfaces between the mild steel and the control liquids, it is highly likely that the thermodynamically defined total solid surface energy, $\gamma_{2}$, as defined in equation (4), will be higher than the sum of the dispersive, $\gamma^{\mathrm{d}}$, and the polar, $\gamma^{\mathrm{p}}$, components of the surface energy.

Table 3 Measured wettability characteristic values for the mild steel before and after HPDL treatment $(1500 \mathrm{~mm} / \mathrm{min}$ traverse speed)

\begin{tabular}{lll}
\hline Characteristics & $\begin{array}{l}\text { Untreated } \\
\text { mild steel }\end{array}$ & $\begin{array}{l}\text { HPDL-treated } \\
\text { mild steel }\end{array}$ \\
\hline Contact angle $(\mathrm{deg})$ & 64 & 23 \\
Surface roughness $\left(R_{\mathrm{a}}\right)(\mu \mathrm{m})$ & 1.46 & 1.12 \\
Relative $\mathrm{O}_{2}$ content $(\%)$ & 34 & 40 \\
Dispersive component, $\gamma_{\mathrm{sv}}^{\mathrm{d}}\left(\mathrm{mJ} / \mathrm{m}^{2}\right)$ & 64.6 & 66.2 \\
Polar component, $\gamma_{\mathrm{sv}}^{\mathrm{p}}\left(\mathrm{mJ} / \mathrm{m}^{2}\right)$ & 4.2 & 6.6 \\
\hline
\end{tabular}

Although the increase in (excess) surface free energy will probably be less than the increase in the total lattice energy, on the other hand an absorbed liquid layer may shield the ionic fields substantially. As such, all the data derived from equations (5) to (11) should be considered as being semi-empirical. Notwithstanding this, as the studies by Gutowski et al. [6] and Agathopoulos and Nikolopoulos [27] found, it is reasonable to conclude from the data obtained from equations (5) to (11) that HPDL treatment of the mild steel surface has caused a small increase in the polar component, $\gamma^{\mathrm{p}}$, of the surface energy.

\subsection{Bonding mechanisms}

On the basis of the nature of the attractive forces existing across a liquid-solid interface, wetting can be classified into the two broad categories of physical wetting and chemical wetting. In physical wetting the attractive energy required to wet a surface is provided by the reversible physical forces (van der Waals). In chemical wetting adhesion is achieved as a result of reactions occurring between the mating surfaces, giving rise to chemical bonds [31].

In practice, complex combination s of various bonding mechanisms actually occur, varying according to the types of materials used [31]. For the mild steel and the enamel, the mechanisms involved in the bonding are principally physical bonding (van der Waals forces), mechanical bonding, chemical bonding (oxide transformation and $\mathrm{O}_{2}$ bridging) and, on a very small scale, electrochemical reactions such as the electrolytic (redox) effect due to the presence of ferric oxides within the mild steel reacting with other oxides in the enamel [31]. Invariably, the preponderant bonding mechanisms between mild steels and enamels are physical and mechanical bonding [32]. However, an EDX analysis conducted at the interface between the mild steel and the enamel revealed the presence of a small diffusion region which contained elements unique to both the mild steel and the enamel. This is perhaps to be expected since enamel glazes on steels are typically bonded as a result of some of the base material dissolving into the glaze [31], with wetting characteristics often being achieved or enhanced by a reaction at the interface at an elevated temperature [33]. Indeed, when an oxide layer is present on the surface of a metal, as was the case for the HPDL-treated mild steel, then typically the fired enamel dissolves this oxide layer. Subsequently a redox reaction has to occur at the interface to form more metal oxide [33]. In the case of the HPDL-treated mild steel and the enamel, which is an $\mathrm{Fe}-\mathrm{CoO}-$ sodium silicate glass system, because the oxidation potential for $\mathrm{Fe}$ is higher than that for $\mathrm{Co}$, the redox reaction forms $\mathrm{FeO}$ at the interface. Thus a layer of $\mathrm{FeO}$ continually remains at the interface and acts as 


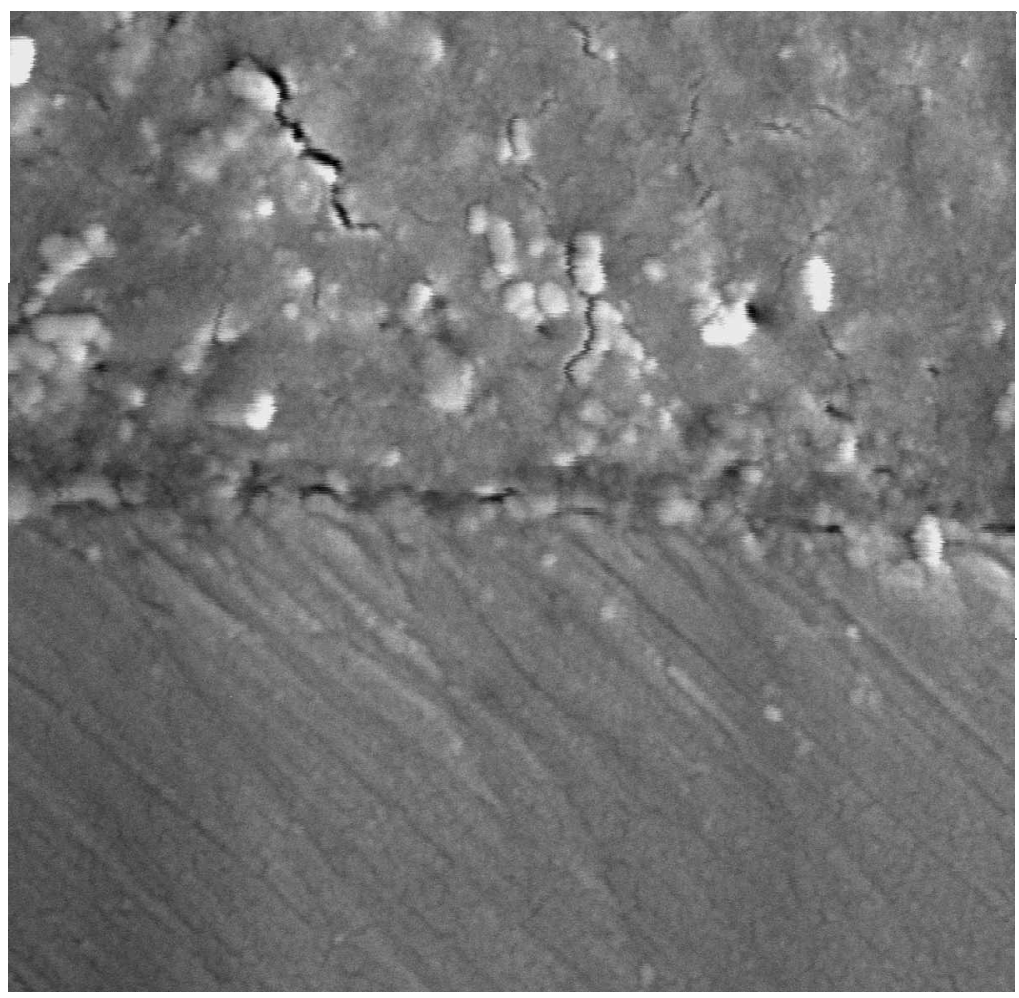

Fig. 5 Typical cross-sectional SEM image of the bond region between the enamel and the HPDL-treated mild steel

the compatible oxide phase that provides the chemical bonding between the HPDL-treated mild steel and the enamel [33]. In addition, intrinsic within the redox reaction formation of $\mathrm{FeO}$ is the alloying of the $\mathrm{Fe}$ with the reduced Co to form dendrites in the interfacial zone by means of a microgalvanic cell mechanism [32, 33]. Furthermore, this alloying has a negative free energy which therefore contributes to the driving force for the net redox reaction formation of $\mathrm{FeO}$ [33].

As one can see from Fig. 5, it is not possible to discern any dendritic growth within the enamel glaze in the bond region, which is characteristic of enamels fired onto substrates containing $\mathrm{Fe}, \mathrm{Si}$ and in particular $\mathrm{Co}$ [32]. However, it can be seen that enamel is held firm in the surface irregularities, thus ensuring sound adhesion.
Again, such mechanical bonding is typical of enamel glazes on metals [32].

\section{MECHANICAL, PHYSICAL AND CHEMICAL CHARACTERISTICS}

\subsection{Bond strength}

To determine the strength of the bond between the conventionally fired and HPDL-fired enamel glazes, pull-off tests based on ASTM C 313-59 [34] were conducted as shown in Fig. 6. For the tests, small samples were prepared $(20 \mathrm{~mm} \times 20 \mathrm{~mm})$. Highly tensile aluminium test dollies were then attached on to both the glazed surface

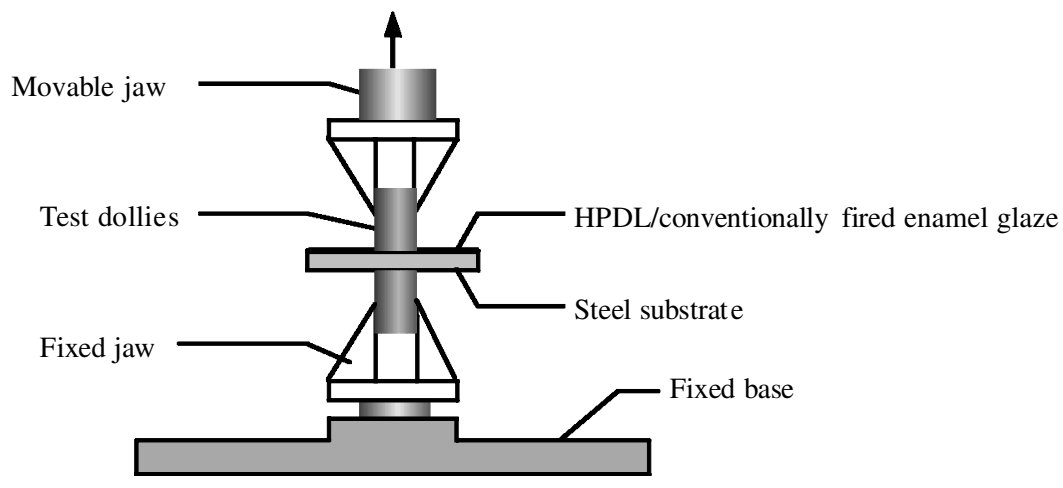

Fig. 6 Schematic of the experimental set-up for the pull-off tests 
Table 4 Recorded values for selected mechanical and physical properties of a conventional and an HPDL-fired enamel glaze

\begin{tabular}{lll}
\hline & \multicolumn{2}{l}{ Enamel glaze firing technique } \\
\cline { 2 - 3 } Mechanical physical property & Conventional & HPDL \\
\hline Mean bond strength $(\mathrm{MPa})$ & 77 & 70 \\
Mean rupture/impact strength $(\mathrm{J})$ & 4.8 & 4.3 \\
Mean surface roughness $\left(R_{\mathrm{a}}\right)(\mu \mathrm{m})$ & 0.55 & 1.88 \\
Wear $($ after $8 \mathrm{~h})\left(\mathrm{mg} / \mathrm{cm}^{2}\right)$ & 93 & 85 \\
\hline
\end{tabular}

and to the axially opposite steel substrate surface using Araldite epoxy and left to cure for $24 \mathrm{~h}$. In order to ensure axial accuracy (essential for true results), the test dollies were set in position using identical Vblocks. The samples were placed into an Instron 4507 tensile/compressive test rig by mounting the test dollies into the jaws of the rig. A tensile force was then applied until failure with the energy being simultaneously recorded.

The mean maximum bond strength of the conventionally fired enamel glaze was recorded as $77 \mathrm{MPa}$, while that of the HPDL-generated glaze was $70 \mathrm{MPa}$, as shown in Table 4. In addition, no discernible difference in the results obtained was observed within the optimum laser operating parameters, indicating that neither the power density nor the traverse speed influenced the bond strength of the enamel glaze. Furthermore, a post-test analysis of both the conventionally fired and the HPDL-fired enamel glazes revealed that the glazes failed mainly around the enamel-steel interface. However, as is typical of well-bonded enamel glazes on steel substrates, small amounts of the enamel glaze remained bonded to the steel. Notwithstanding this, according to Vargin [32] it is still reasonable to assume that bond strength values obtained are valid, since most of the glaze failed at the interface rather than within the glaze itself.

It is proposed that the close agreement of the recorded mean maximum bond strength of the conventionally fired and the HPDL-generated enamel glazes can be attributed to the fact that the HPDL-generated glaze displayed bonding mechanisms similar to those of a conventionally fired glaze.

\subsection{Rupture/impact strength}

Tests were conducted to determine the rupture/impact strength of the conventionally fired and HPDL-fired enamel glazes. The tests were carried out as shown in Fig. 7, while the test samples were prepared as described above. The samples were placed onto the sample stage of the Instron 4507 tensile/compressive test rig and then subjected to a compressive rupture/impact force until the enamel glazes failed (cracked), with the energy being simultaneously recorded. The rupture/impact force was applied by means of a highly tensile steel indenter with a $1 \mathrm{~mm}$ radius point.

The results of the tests are given in Table 4. As can be seen, there was little difference in the recorded values of average rupture strength for the conventionally fired enamel glaze and the HPDL-generated glaze, 4.8 and $4.3 \mathrm{~J}$ respectively. Again, no discernible difference in the results obtained was observed within the optimum laser operating parameters, indicating that neither the power density nor the traverse speed influenced the rupture/impact strength of the enamel glaze.

It is suggested that such similar values of rupture/ impact strength were the result of both the conventionally fired and the HPDL-generated glaze possessing very similarly shaped cross-sections, that is a flat interface with the steel substrate and an almost flat upper surface. Indeed, the relatively small difference between the recorded rupture/impact strengths of the conventionally fired and HPDL-generated glazes is probably due mainly to the fact that the upper surface of the HPDLfired glaze exhibited a very slightly concave surface geometry. Thus, the strains within the enamel layer were marginally higher and thus reduced the strength in comparison with an enamel seal with a flat upper

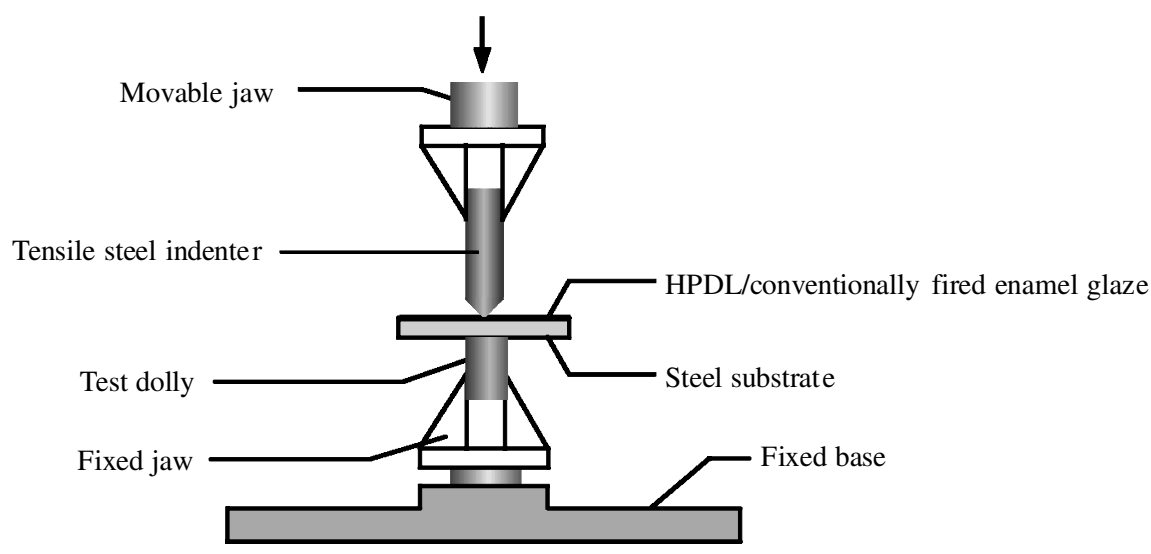

Fig. 7 Schematic of the experimental set-up for the rupture/impact tests 


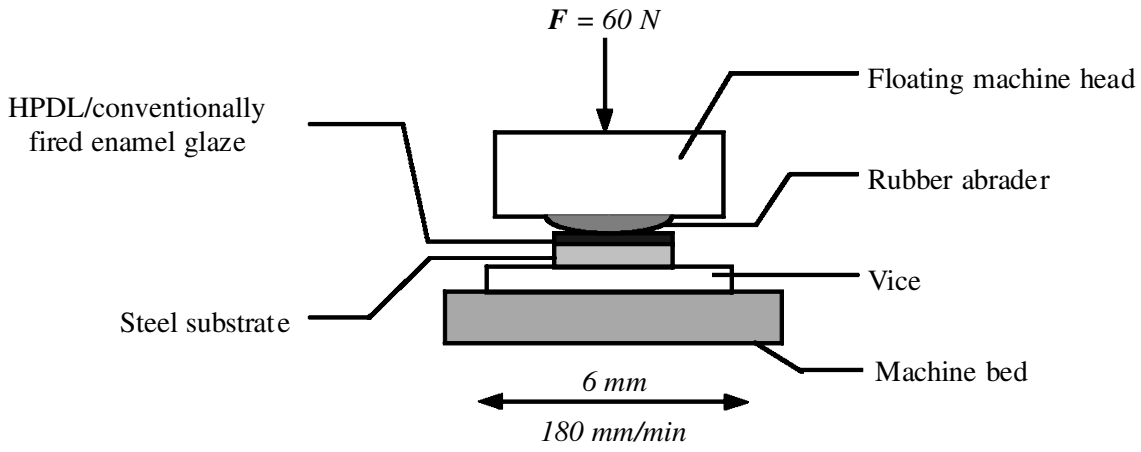

Fig. 8 Schematic of the experimental set-up for the wear tests

surface profile, as was the case with the conventionally fired enamel glaze [32].

\subsection{Surface roughness}

An important feature of any enamel glaze is its surface roughness, since it is this property that invariably determines the functionality and cleanability of the surface. Using a Taylor-Hobson Surtronic 3+ surface texture measuring instrument, a series of measurements was taken on the conventionally fired and HPDL-fired enamel glazes. On each sample four measurements were made in different positions and in different directions on the surface, with an average being taken. Table 4 summarizes the surface roughness $\left(R_{\mathrm{a}}\right)$ measurement results.

As is apparent from Table 4, the surface roughness of the conventionally fired enamel glaze was significantly less than that of the HPDL-fired enamel glaze, $0.55 \mu \mathrm{m}$ compared with $1.88 \mu \mathrm{m}$ respectively. Clearly, in this situation the surface roughness, and therefore the cleanability, of the conventionally fired enamel glaze will be considerably better. It is believed that this variation in surface roughness is due to the vastly different firing times of the two processes (hours in the conventional manner and seconds for the HPDL technique) and the particle size of the enamel frit itself. Since the firing times are somewhat fixed, it is postulated that the problem of a rougher surface resulting from the HPDL technique could be overcome by using smaller enamel particles, an approach that would not greatly improve the result when firing in the conventional manner.

\subsection{Wear life}

Primarily, the wear resistance of a material is in general determined by the hardness of the material in comparison with the hardness of other materials with which it subsequently comes into contact [35]. However, wear resistance does not always increase with hardness [36]. Tests were therefore conducted in accordance with the procedure detailed by Lawrence and Spencer [16], based on ASTM C 448-64 [37], to determine the exact difference in the wear resistance characteristics of the conventionally fired and the HPDL-generated enamel glazes (Fig. 8). For experimental purposes the glazed samples were cut into smaller pieces $(25 \mathrm{~mm} \times 25 \mathrm{~mm})$. All the samples were then weighed and subjected to a friction force for $8 \mathrm{~h}$, being removed from the machine and weighed at $2 \mathrm{~h}$ intervals.

Figure 9 shows the relationship between weight loss and the friction time for the laser-generated OPC glazes and the untreated OPC. As is evident from Fig. 9, both glazes displayed an exceedingly high degree of wear resistance. Further, practically no difference in the wear resistance of the two glazes was observed. Arguably, this indicates that the two glazes possess the same mechanical properties and similar amorphous structure, despite their very different firing techniques. This is, perhaps, a valid argument when one considers the previous findings of this work.

\subsection{Corrosion resistance}

Enamelled surfaces are often subjected to corrosive substances, as part of the normal service environment and/ or as a result of routine cleaning. Corrosion resistance tests based on BS 6428 [38] were therefore conducted using nitric acid, sodium hydroxide and Premier Products MP9 detergent cleaner. The experiments were carried out by dropping small amounts of the corrosive agents, in the concentration ratios of $80,60,40,20$ and 10 per cent, onto the surfaces of the conventionally fired and HPDL-generated enamel glazes at hourly intervals for $4 \mathrm{~h}$. The samples were then examined optically and mechanically tested in terms of bond strength, rupture/impact strength and wear life. High concentrations of the various corrosive agents were used principally to accelerate the tests.

Both the conventionally fired and the HPDLgenerated enamel glazes displayed complete resistance to all three substances, even at the highest concentrations. However, perhaps more importantly, even when exposed to the highest concentrations, no discernible effect on the bond strength, rupture/impact strength and wear life of either enamel glaze was observed. 


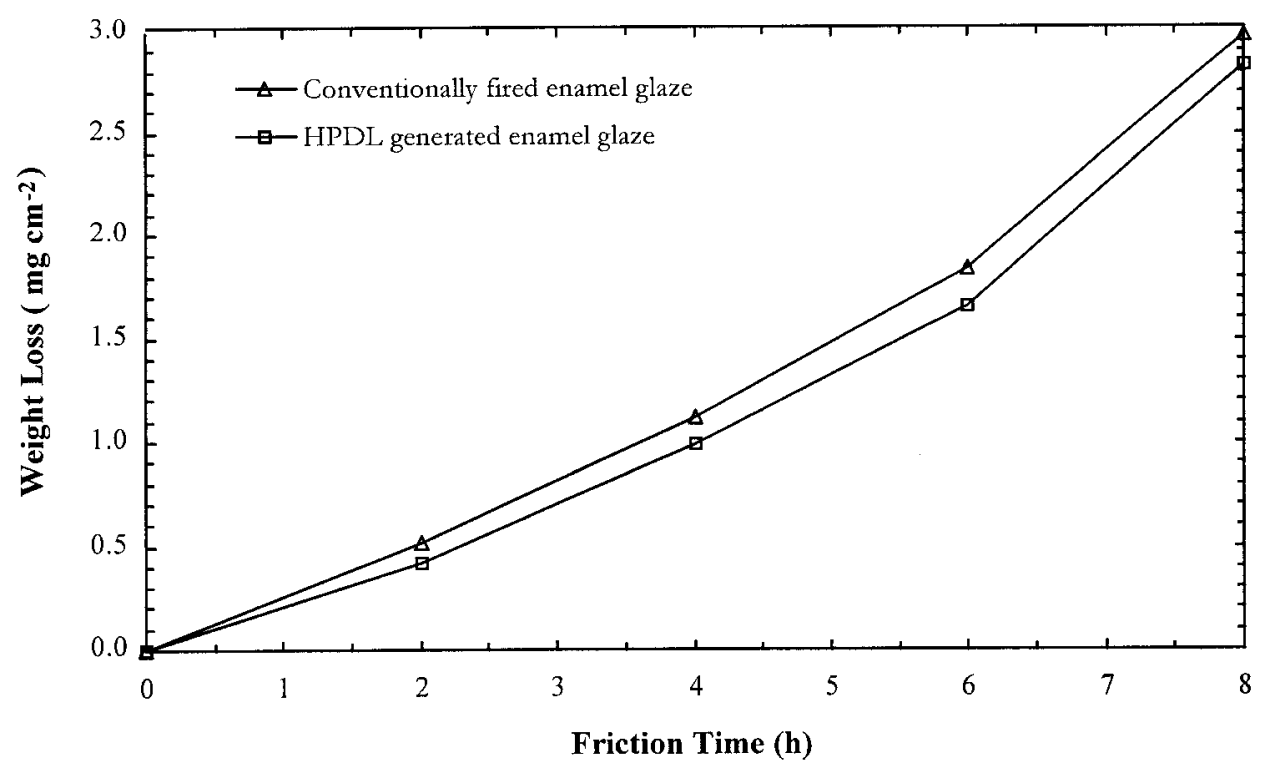

Fig. 9 Relationship between mass loss and friction time for the conventionally fired and HPDL-generated enamel glazes

Furthermore, no discernible microstructural changes or signs of devitrification due to corrosion were seen in either glaze. Again, this is perhaps a strong indication that the two glazes possess a similar amorphous structure, despite their very different firing techniques.

\section{CONCLUSIONS}

HPDL surface treatment of the mild steel effected significant changes in the wettability characteristics of the mild steel. Moreover, the HPDL surface treatment made it possible to fire an enamel glaze directly onto the EN8 carbon steel substrate in normal atmospheric conditions after HPDL surface pre-treatment, but without pretreatment chemical cleaning of the steel. Furthermore, through the employment of the HPDL, the whole enamel firing process was reduced from one taking hours to complete to one that was complete in minutes. Table 4 summarizes the effects of HPDL surface treatment on the steel. Improvements in the wetting action of the mild steel after HPDL treatment were identified as being due to (a) the HPDL-induced melting of the mild steel surface which brought about a reduction of the surface roughness, thus directly reducing the contact angle, $\theta$, (b) the small increase in the polar component of the surface energy, $\gamma_{\mathrm{sv}}^{\mathrm{p}}$, after HPDL treatment (which is thought to be due to the HPDL-effected microstructural changes), thus improving the action of wetting and adhesion, and (c) the increase in the surface $\mathrm{O}_{2}$ content of the mild steel resulting from HPDL treatment identified as further promoting the action of wetting.

Mechanical, physical and chemical testing of the HPDL-fired enamel glaze revealed the glaze to possess similar properties to those of a conventionally fired enamel glaze. The mean average bond strength of the HPDL-fired enamel glaze was recorded as $70 \mathrm{MPa}$; this compares with $77 \mathrm{MPa}$ for a conventionally fired enamel glaze. The average rupture strength for the conventionally fired enamel glaze and the HPDL-generated glaze were recorded as 4.8 and $4.3 \mathrm{~J}$ respectively. Exceptional wear and corrosion resistance was displayed by both the HPDL- and the conventionally fired enamel glazes, with both only wearing by around $2.8 \mathrm{mg} / \mathrm{cm}^{2}$ after $8 \mathrm{~h}$ and both showing complete resistance to acid, alkali and detergent attack. It is believed that such results are due to the two glazes possessing the same mechanical properties and similar amorphous structure, despite their very different firing techniques. The surface roughness, however, of the conventionally fired enamel glaze was significantly less than that of the HPDL-fired enamel glaze, $0.55 \mu \mathrm{m}$ compared with $1.88 \mu \mathrm{m}$ respectively. It is believed that this variation in surface roughness is due to the vastly different firing times of the two processes (hours in the conventional manner and seconds for the HPDL technique) and the particle size of the enamel frit itself. It is postulated that the problem of a rougher surface resulting from the HPDL technique could be overcome by using smaller enamel particles.

\section{REFERENCES}

1 Ueki, M., Naka, M. and Okamoto, I. Wettability of some metals against zirconia coatings, J. Mater. Sci. Lett., 1986, 5, 1261-1262.

2 Nikopoulos, P. and Sotiropoulou, D. Wettability between zirconia ceramics and the liquid metals copper, nickel and cobalt. J. Mater. Sci. Lett., 1987, 6, 1429-1430. 
3 Chidambaram, P. R., Edwards, G. R. and Olson, D. L. A thermodynamic criterion to predict wettability at metalalumina interfaces. Metallurgical Trans. B, 1992, 23, 215-222.

$4 \mathbf{L i}, \mathbf{J}$. G. Role of electron density of liquid metals and bandgap energy of solid ceramics on the work of adhesion and wettability of metal-ceramic systems. J. Mater. Sci. Lett., 1992, 11, 903-905.

5 Li, J. G. Chemical trends in the thermodynamic adhesion of metal/ceramic systems. Mater. Lett., 1995, 22, 169-174.

6 Gutowski, V. W., Russell, L. and Cerra, A. Adhesion of silicone sealants to organic-coated aluminium. In Science and Technology of Building Seals, Sealants, Glazing and Waterproofing (Ed. J. M. Klosowski), 1992, pp. 144-159 (American Society for Testing and Materials, Philadelphia, Pennsylvania).

7 Zhou, X. B. and de Hosson, J. Th. M. Microstructure and interfaces of a reaction coating on aluminium alloys by laser processing. J. Phys. Paris, IV, 1993, 3, 1007-1011.

8 Zhou, X. B. and de Hosson, J. Th. M. Metal-ceramic interfaces in laser coated aluminium alloys. Acta Metall. Mater., 1994, 42, 1155-1162.

9 Li, J. G. Microscopic approach of adhesion and wetting of liquid metal on solid ionocovalent oxide surface. Rare Metals, 1993, 12, 84-96.

10 Heitz, J., Arenholz, E., Kefer, T., Bäuerle, D., Hibst, H. and Hagemeyer, A. Enhanced adhesion of metal films on PET after uv-laser treatment. Appl. Phys. A, 1992, 55, 391-392.

11 Henari, F. and Blau, W. Excimer laser surface treatment of metals for improved adhesion. Appl. Opt., 1995, 34, 581-584.

12 Olfert, M., Duley, W. and North, T. Laser treatment for adhesive bonding in coated steels. In Laser Processing (Ed. J. Mazumder), 1996, pp. 479-490 (Kluwer, Amsterdam).

13 Lawrence, J. and $\mathbf{L i}, \mathbf{L}$. Wettability characteristics of a mild steel modified with $\mathrm{CO}_{2}, \mathrm{Nd}: \mathrm{YAG}$, excimer and high power diode lasers. J. Phys. D, 1999, 32, 2311-2318.

14 Lawrence, J., Li, L. and Spencer, J. T. Ceramic tile grout removal and tile sealing using high power lasers. In Proceedings of ICALEO'96 on Laser Materials Processing, Detroit, Michigan, 1996, pp. 138-148 (Laser Institute of America, Orlando, Florida).

15 Lawrence, J., Li, L. and Spencer, J. T. A two-stage ceramic tile grout sealing process using a high power diode laser. Part I: grout development and materials characteristics. Opt. Laser Tech., 1998, 30, 205-214.

16 Lawrence, J., Li, L. and Spencer, J. T. A two-stage ceramic tile grout sealing process using a high power diode laser. Part II: mechanical, chemical and physical properties. Opt. Laser Tech., 1998, 30, 215-223.

17 Lawrence, J. PhD thesis, University of Manchester Institute of Science and Technology, 1999.

18 Bourell, D. L., Marcus, H. L., Barlow, J. W. and Beaman, J. J. Selective laser sintering of metals and ceramics. Int. J. Powder Metall., 1992, 28, 369-381.

19 Agarwala, M., Bourell, D. L., Beaman, J. J., Marcus, H. L. and Barlow, J. W. Direct laser sintering of metals. Rapid Prototyping J., 1995, 1, 26-36.
20 Jaycock, M. J. and Parfitt, G. D. Chemistry of Interfaces, 1984 (John Wiley, London).

21 Wenzel, R. N. Resistance of solid surfaces to wetting by water. Ind. Engng Chem., 1936, 28, 988-994.

22 Cassie, A. B. D. and Baxter, S. Wettability of porous surfaces. Trans. Faraday Soc., 1944, 40, 546-551.

23 Zhou, X. B. and de Hosson, J. Th. M. Influence of surface roughness on the wetting angle. J. Mater. Res., 1995, 10, 1984-1992.

24 Neumann, A. W. and Good, R. J. Thermodynamics of contact angles. I: heterogeneous solid surfaces. J. Colloid Interface Sci., 1972, 38, 341-358.

25 Nicolas, G., Autric, M., Marine, W. and Shafeev, G. A. Laser induced surface modifications on $\mathrm{ZrO}_{2}$ ceramics. Appl. Surf. Sci., 1997, 109-110, 289-292.

26 Feng, A., McCoy, B. J., Munir, M. A. and Cagliostro, D. Wettability of transition metal oxide surfaces. Mater. Sci. Engng A, 1998, 1-2, 50-56.

27 Agathopoulos, S. and Nikolopoulos, P. Wettability and interfacial interactions in bioceramic-body-liquid systems. J. Biomed. Mater. Res., 1995, 29, 421-429.

28 Fowkes, F. M. Attractive forces at interfaces. Ind. Engng Chem., 1964, 56, 40-52.

29 Chattoraj, D. K. and Birdi, K. S. Adsorption and the Gibbs Surface Excess, 1984, p. 95 (Plenum, New York).

30 Girifalco, L. A. and Good, D. J. A theory for the estimation of surface and interfacial energies. III: estimation of surface energies of solids from contact angle data. J. Phys. Chem., 1960, 64, 561-565.

31 Greenhut, V. A. Surface considerations for joining ceramics and glasses. In Engineered Materials Handbook: Adhesives and Sealants (Ed. H. F. Brinson), 1991, pp. 298-311 (ASM International, Metals Park, Ohio).

32 Vargin, V. V. Technology of Vitreous Enamels, 1968 (Academic, New York).

33 Pask, J. A. and Tomisa, A. P. Wetting, surface energies, adhesion and interface reaction thermodynamics. In Engineered Materials Handbook: Ceramics and Glasses (Ed. S. J. Schneider), 1991, pp. 482-492 (ASM International, Metals Park, Ohio).

34 ASTM C 313-59: Part 17: 1977 Adherence of Porcelain Enamels and Ceramic Coatings to Sheet Metal, 1977 (American Society for Testing and Materials, Philadelphia, Pennsylvania).

35 Dickson, J. H. Glass: A Handbook for Students and Technicians, 1951, p. 148 (Hutchinsons Scientific and Technical Publications, London).

36 Petitbon, A., Boquet, L. and Delsart, D. Laser surface sealing and strengthening of zirconia coatings. Surf. Coatings Technol., 1991, 49, 57-61.

37 ASTM C 448-64: Part 17: 1977 Abrasion Resistance of Porcelain Enamels, 1977 (American Society for Testing and Materials, Philadelphia, Pennsylvania).

38 BS 6428: Part 8: 1985 Porcelain Enamels on Steel: A Method for Determination of Chemical Resistance, 1985 (British Standards Institution, London). 
Copyright of Proceedings of the Institution of Mechanical Engineers -- Part B -Engineering Manufacture is the property of Professional Engineering Publishing and its content may not be copied or emailed to multiple sites or posted to a listserv without the copyright holder's express written permission. However, users may print, download, or email articles for individual use. 